\title{
Mental Health among Married Men and Women
}

\author{
Vikas K. Rohit ${ }^{1}$ *
}

\section{ABSTRACT}

Aim of the study is to find out the mental health among married men and women so investigator selected two groups one is low age of married men and women and other is high age of men and women, both groups have 30 respondents. In one group has 19 low age of married men and women and other one groups has 11 high age of married men and women. Data were collected from anand city. Scale was use for data collection is personal datasheet and mental health scale developed by bhatt and geeda (1992) and data were analysis through ' $t$ ' test. Result show, There is no significant mean difference of mental health between low and high age of married men and women. There is no significant mean difference of the mental health of joint and nuclear family of married men and women.

Keywords: Mental Health, Married Men and Women

Mental health is a level of psychological well-being, or an absence of a mental disorder; it is the "psychological state of someone who is functioning at a satisfactory level of emotional and behavioural adjustment".

Mental health is a state of well-being in which a person understands his or her own abilities, can cope with the normal stresses of life, can work productively and fruitfully and is able to make a contribution to his or her community.

The expression “Mental Health “ Consist of two words Mental and Health', 'Health' generally means sound conditions or well being or freedom from desire, Mental Health therefore means a sound mental condition or a state of psychological well being of freedom from mental daises.(Sing 2004)

Mental health can be seen as an unstable continuum, where an individual's mental health may have many different possible values. Mental wellness is generally viewed as a positive attribute, even if the person does not have any diagnosed mental health condition. This definition of

\footnotetext{
${ }^{1}$ PhD Research Scholar, Department of Psychology, S P University, V.V.Nagar, Gujarat, India *Responding Author

(C) 2016 Rohit V; licensee IJIP. This is an Open Access Research distributed under the terms of the Creative Commons Attribution License (http://creativecommons.org/licenses/by/2.0), which permits unrestricted use, distribution, and reproduction in any Medium, provided the original work is properly cited.
} 


\section{Mental Health among Married Men and Women}

mental health highlights emotional well-being, the capacity to live a full and creative life, and the flexibility to deal with life's inevitable challenges. Some discussions are formulated in terms of contentment or happiness. Many therapeutic systems and self-help books offer methods and philosophies espousing strategies and techniques vaunted as effective for further improving the mental wellness. Positive psychology is increasingly prominent in mental health.

Mental health and stability is a very important factor in a person's everyday life. Social skills, behavioural skills, and someone's way of thinking are just some of the things that the human brain develops at an early age. Learning how to interact with others and how to focus on certain subjects are essential lessons to learn from the time we can talk all the way to when we are so old that we can barely walk. However, there are some people out there who have difficulty with these kinds of skills and behaving like an average person. This is a most likely the cause of having a mental illness. A mental illness is a wide range of conditions that affect a person's mood, thinking, and behaviour. About 26\% of people in the United States, ages 18 and older, have been diagnosed with some kind of mental disorder.

\section{Aims Of The Study:}

1. To study of the mental health among low and high age of married men and women.

2. To study of the mental health among joint and nuclear family of married men and women.

\section{Hypothesis:}

1. There is no significant difference between the mental health of low and high age of married men and women.

2. There is no significant difference between the mental health of joint and nuclear family of married men and women.

\section{METHOD}

\section{Sample:}

For this research 43 male and female were taken as sample from anand city primary school teachers. Out of that only 30 samples randomly selected, which are 19 low and 11 high age of male and female.

\section{Tools used:}

The following tools were used in the present study:

\section{Personal Data sheet:}

Certain personal information about respondents included in the sample of research is useful and important for study. Here also, for collecting such important information, personal data sheet was prepared. With the help of this personal data sheet, the information about types of age and types of family was collected.

In this research following tools are used: 


\section{Mental Health among Married Men and Women}

\section{Mental health scale}

Mental health scale was developed by bhatt and geeda (1992). It contains 40 items to measure the mental health. It is meant for any group.

\section{Statistical Analysis:}

In this study 't' test was used for statistical analysis.

\section{RESULT AND DISCUSSION}

Table no.1, (N=30), Means, SDs and't' value of mental health with reference to Type of Age:

\begin{tabular}{|c|c|c|c|c|}
\hline Type of Age & $\mathbf{N}$ & Mean & SD & 't' value \\
\hline Low & 19 & 40.37 & 3.59 & \multirow{2}{*}{$1.52(\mathrm{NS})$} \\
\hline High & 11 & 38.09 & 4.13 & \\
\hline \multicolumn{5}{|c|}{ NS= Not significant } \\
\hline
\end{tabular}

It is revealed in Table No.1 that mean score of mental health in married men and women belonging to low and high ages are 40.37 and 38.09 respectively. These means indicate that married men and women of low ages experienced the highest level of mental health (40.37) as compared to the married men and women of high ages (38.09).The result indicate this as first sight when 't' value was calculated to know statistical significant of mean difference, insignificant difference was observed between low and high ages of married men and women. ' $\mathrm{t}$ ' value is 1.52 (Table no.1) which is statistically insignificant. Hence the null hypothesis (No.1) was accepted. Thus the results show that type of age has no significant effect on mental health.

Table no.2, ( $N=30)$, Means, $S D$ and ' $t$ ' value of mental health with reference to Type of family

\begin{tabular}{|c|c|c|c|c|}
\hline Type of Family & $\mathbf{N}$ & Mean & SD & t value \\
\hline Joint & 19 & 40.94 & 3.77 & $1.20(\mathrm{NS})$ \\
\hline Nuclear & 11 & 38.90 & 4.82 & \\
\hline \multicolumn{2}{|c|}{ NS = Not Significant } \\
\hline
\end{tabular}

It is revealed in Table No.2 that mean score of mental health in married men and women belonging to joint and nuclear families are 40.94 and 38.90 respectively. These means indicate that married men and women of joint families experienced the highest level of mental health (40.94) as compared to the married men and women of nuclear families (38.90).The result indicate this as first sight when't' value was calculated to know statistical significant of mean difference, insignificant difference was observed between joint and nuclear families of married men and women. 't' value is 1.20 (Table no.2) which is statistically insignificant. Hence the null hypothesis (No.2) was accepted. Thus the results show that type of families has no significant effect on mental health.

\section{CONCLUSION}

1. There is no significant difference between the mental health of low and high ages of married men and women. 


\section{Mental Health among Married Men and Women}

2. There is no significant difference between the mental health of joint and nuclear families of married men and women.

\section{Acknowledgments}

The author appreciates all those who participated in the study and helped to facilitate the research process.

\section{Conflict of Interests}

The author declared no conflict of interests.

\section{REFERENCES}

Govt of Canada (2016) Canadian centre for occupational health and safety.

Graham, Michael C. (2014). Facts of Life: ten issues of contentment. Outskirts Press, ISBN-9781-4787-2259-5, pp. 6-10.

Keyes, Corey (2002).The mental health continuum: from languishing to flourishing in life, Journal of Health and Social Behaviour 43 (2), Doi-10.2307/3090197. JSTOR 3090197, pp-207-222.

Nandoliya, H.G. (2013) A Study of Mental Health of Higher Secondary School Teachers In Relation To Sex, Habitat, Types of Schools And Faculty, acme International Journal of Multidisciplinary Research, Volume, 1, issue 4, ISSN-2320-236x, pp-23-30.

Singh, A., Walia, G.S. (2004). Health and Physical Education, Vinod Publications Ludhiana. Wikipedia, Revisited from, https://en.wikipedia.org/wiki/Mental_health.

How to cite this article: Rohit V (2016), Mental Health among Married Men and Women, International Journal of Indian Psychology, Volume 4, Issue 1, No. 81, ISSN:2348-5396 (e), ISSN:2349-3429 (p), DIP:18.01.121/20160401, ISBN:978-1-365-59365-9 